\title{
Inter-arm Differences in Simultaneous Blood Original Inter-arm Differences in Simultaneous Blood Article Pressure Measurements in Ambulatory Patients without Cardiovascular Diseases
}

\author{
Kyoung Bog Kim, Mi Kyeong Oh*, Haa Gyoung Kim, Ji Hoon Ki, Soo Hee Lee, \\ Su Min Kim
}

Department of Family Medicine, Gangneung Asan Hospital, University of Ulsan College of Medicine, Gangneung, Korea

Background: It has traditionally been known that there is normally a difference in blood pressure (BP) between the two arms; there is at least $20 \mathrm{~mm} \mathrm{Hg}$ difference in the systolic blood pressure (SBP) and $10 \mathrm{~mm} \mathrm{Hg}$ difference in the diastolic blood pressure (DBP). However, recent epidemiologic studies have shown that there are between-arm differences of $<$ $5 \mathrm{~mm} \mathrm{Hg}$ in simultaneous BP measurements. The purposes of this study is to examine whether there are between-arm differences in simultaneous BP measurements obtained from ambulatory patients without cardiovascular diseases and to identify the factors associated these differences.

Methods: We examined 464 patients who visited the outpatient clinic of Gangneung Asan Hospital clinical department. For the current analysis, we excluded patients with ischemic heart disease, stroke, arrhythmia, congestive heart failure, or hyperthyroidism. Simultaneous BP measurements were obtained using the Omron MX3 BP monitor in both arms. The inter-arm difference (IAD) in BP was expressed as the relative difference (right-arm BP $[\mathrm{R}]$ minus left-arm $\mathrm{BP}[\mathrm{L}]$ : R - L) and the absolute difference $(|\mathrm{R}-\mathrm{L}|)$.

Results: The mean absolute IAD in SBP and DBP were $3.19 \pm 2.38$ and $2.41 \pm 1.59 \mathrm{~mm} \mathrm{Hg}$, respectively, in men and $2.61 \pm 2.18$ and $2.25 \pm 2.01 \mathrm{~mm} \mathrm{Hg}$, respectively, in women. In men, there were $83.8 \%$ of patients with the IAD in SBP of $\leq 6 \mathrm{~mm} \mathrm{Hg}$, $98.1 \%$ with the IAD in SBP of $\leq 10 \mathrm{~mm} \mathrm{Hg}, 96.5 \%$ with the IAD in DBP of $\leq 6 \mathrm{~mm} \mathrm{Hg}$ and $0 \%$ with the IAD in DBP of $>10$ $\mathrm{mm} \mathrm{Hg}$. In women, $89.6 \%$ of patients had IAD in SBP of $\leq 6 \mathrm{~mm} \mathrm{Hg}, 92.1 \%$ with IAD in DBP of $\leq 6 \mathrm{~mm} \mathrm{Hg}$, and $0 \%$ with IAD in SBP of $>10 \mathrm{~mm}$ Hg or IAD in DBP of $>10 \mathrm{~mm} \mathrm{Hg}$. Gangneung Asan Hospital clinical series of patients showed that the absolute IAD in SBP had a significant correlation with cardiovascular risk factors such as the 10-year Framingham cardiac risk scores and higher BP in men and higher BP in women. However, the absolute IAD in SBP and DBP had no significant correlation with the age, obesity, smoking, drinking, hyperlipidemia, diabetes, metabolic syndrome, and renal function.

Conclusion: Our results showed that there were no significant between-arm differences in simultaneous BP measurements. It was also shown that most of the ambulatory patients without cardiovascular diseases had an $\mathrm{IAD}$ in $\mathrm{SBP}$ of $<10 \mathrm{~mm} \mathrm{Hg}$ and an $\mathrm{IAD}$ in $\mathrm{DBP}$ of $<6 \mathrm{~mm} \mathrm{Hg}$.

Keywords: Blood Pressure Determination; Arm; Risk Factors; Adults

Received: August 30,2011, Accepted: December 27, 2012

*Corresponding Author: Mi Kyeong Oh

Tel: +82-33-610-3325, Fax: +82-33-641-8066

E-mail: omk@gnah.co.kr

Korean Journal of Family Medicine

Copyright (C) 2013 The Korean Academy of Family Medicine

(a) This is an open-access article distributed under the terms of the Creative Commons Attribution Non-Commercial License (http://creativecommons.org/licenses/by-nc/3.0) which permits unrestricted noncommercial use, distribution, and reproduction in any medium, provided the original work is properly cited.

\section{INTRODUCTION}

Accurate measurement of blood pressure (BP) is essential not only for diagnosing hypertension but also for identifying major cardiovascular risk factors. Thus, it contributes to lowering cardiovascular mortality. It is routine clinical practice to measure $\mathrm{BP}$ in both arms. If there is a discrepancy in BP between the two arms, the BP is measured again. Then, it is recommended that the BP be measured on the higher side. ${ }^{1)}$ Most patients may normally 
show a difference in BP between the two arms. But if there is an inter-arm difference (IAD) in the systolic blood pressure (SBP) of $\geq 20 \mathrm{~mm} \mathrm{Hg}$ and that in the diastolic blood pressure (DBP) of $\geq 10 \mathrm{~mm} \mathrm{Hg}$, the corresponding patients would be suspected of having vascular anomaly or coarctation of the aorta. ${ }^{2)}$ The greater $\mathrm{IAD}$ in $\mathrm{BP}$ is indicative of atherosclerotic peripheral diseases, leading to cardiovascular morbidity and mortality. ${ }^{3,4)}$ Also in Korea, Kim et al. ${ }^{5)}$ detected subclavian steal syndrome due to atherosclerosis in patients with an IAD in SBP of $35 \mathrm{~mm} \mathrm{Hg}$ and then treated them. This highlights the significance of the IAD in BP following its measurement in both arms.

It has been accepted that the IAD in SBP and DBP should be smaller than $20 \mathrm{~mm} \mathrm{Hg}$ and $10 \mathrm{~mm} \mathrm{Hg}$, respectively. With the intravascular measurement of BP in both arms in normal healthy individuals, however, there was almost no IAD in BP. The IAD in BP of 10 to $20 \mathrm{~mm} \mathrm{Hg}$ has been regarded as normal in healthy individuals despite a lack of notable difference in the anatomical features between the two arms. Presumably, the IAD in BP might arise from measurement errors due to the status of stabilization and respiration of the patients depending on the order of measurement, because the BP has been measured using a mercury sphygmomanometer sequentially for each arm in the previous studies.

Given the above background, we conducted this study to estimate the IAD in $\mathrm{BP}$ by simultaneously measuring the $\mathrm{BP}$ in both arms using an automatic electronic sphygmomanometer in ambulatory patients without cardiovascular disease, and to identify the cardiovascular risk factors associated with a notable $\mathrm{IAD}$ in $\mathrm{BP}$.

\section{METHODS}

\section{Study Subjects}

The current study was conducted in adult patients aged 40 years or older who visited the outpatient clinic of the department of family medicine of Gangneung Asan Hospital during a period ranging from September of 2010 to May of 2011. Exclusion criteria for the current study were as follows: 1) patients who had a past history of cerebrovascular disease on history taking and physical examination, 2) patients who had a past disease history of specific vascular diseases such as aortic dissection or aneurysm,
3) patients who had a past history of receiving cardiovascular surgery or procedure, 4) patients who had a past history of arrhythmia or the current presence of it on electrocardiogram (EKG), 5) patients who had a past history or current presence of an amputated upper limb because of trauma, 6) patients who were receiving blood dialysis for the upper limbs, 7) patients for whom history taking could not be properly performed, and those whose data was unreliable. Therefore, we enrolled a total of 464 patients $(\mathrm{n}=464)$ who submitted a written informed consent.

\section{Methods for Blood Pressure Measurement}

$\mathrm{BP}$ was measured using the indirect BP measurement method. We invited our patients to refrain from smoking and caffeine intake one hour prior to the measurement of BP. After inviting them to drop by the restroom, we stabilized them in a sitting position for more than ten minutes prior to the measurement of BP. BP was measured using an automatic electronic sphygmomanometer, Omron MX3 (Omron Life Science, Kyoto, Japan). BP measurement was performed by physicians and nurses with more than two years of clinical experience, who palpated the pulse of the brachial artery and then placed the center of cuff s air bag on the palpated region. After placing the lower part of the cuff $2.5 \mathrm{~cm}$ superior to the antecubital fossa, we simultaneously measured the BP in both arms.

In addition, the cuff was released after the first session of the measurement. This was followed by the second session of the measurement that was repeated at a minimal interval of five minutes. If there was a difference of more than $5 \mathrm{~mm} \mathrm{Hg}$ in diastolic pressure in the ipsilateral forearm, BP was measured twice consecutively in both arms after two minutes.

\section{Data Collection}

Prior to data collection, all patients submitted a written informed consent. They were directly interviewed for a past history of smoking, alcohol drinking, and diseases such as hypertension, diabetes mellitus, ischemic heart disease, stroke, arrhythmia, congestive heart failure, and thyroid diseases. In addition, patients also received physical examination, complete blood counts, imaging studies, and EKG. Hypertensive patients were defined as SBP of $\geq 140 \mathrm{~mm} \mathrm{Hg}$ or DBP of $\geq 90 \mathrm{~mm}$ $\mathrm{Hg}$ according to the Seventh Report of the Joint National 
Committee on Prevention, Detection, Evaluation, and Treatment of High Blood Pressure guidelines. Those who were taking antihypertensive drugs were categorized as hypertensive patients regardless of their BP. Furthermore, diabetes mellitus was defined as 8-hour fasting blood sugar of $\geq 126 \mathrm{mg} / \mathrm{dL}$ or hemoglobin $\mathrm{AlC}$ $\geq 6.5 \%$. Participants under diabetic treatments were categorized as diabetic patients regardless of their blood glucose. In addition, on physical examination, the height and weight were measured using the automatic height/weight measurement system. Obesity was defined according to the Asia-Pacific criteria, based on which the patients were divided into two groups based on a cut-off value of body mass index of $25 \mathrm{~kg} / \mathrm{m}^{2}$. In the current study, we used the following diagnostic criteria for metabolic syndrome: 1) SBP $\geq 130 \mathrm{~mm} \mathrm{Hg}$ or DBP $\geq 85 \mathrm{~mm} \mathrm{Hg}$, or the current use of antihypertensive drugs; 2) fasting blood sugar $\geq 100 \mathrm{mg} / \mathrm{dL}$ or the current use of anti-diabetic drugs; 3) triglyceride $\geq 150 \mathrm{mg} / \mathrm{dL}$ or the use of treatment agents; 4) HLD-cholesterol $<40 \mathrm{mg} /$ $\mathrm{dL}$ in men and $<50 \mathrm{mg} / \mathrm{dL}$ in women, or the use of treatment agents; and 5) waist circumference $\geq 90 \mathrm{~cm}$ in men and $\geq 85 \mathrm{~cm}$ in women.

Metabolic syndrome was defined as any patients who met more than three of the above five criteria according to the American Heart Association/National Heart, Lung, and Blood Institute Adult Treatment Panel III 2005 criteria. Framingham cardiac risk scores were calculated according to the methods of Wilson et al. ${ }^{7)}$ The glomerular filtration rate was calculated using the Cockcro-Gault formula where sex, age, and body weight were considered.

\section{Statistical Analysis}

$\mathrm{BP}$ was measured twice in both arms and measurements were averaged. Thus, the mean values of SBP and DBP were obtained. To calculate the IAD in $\mathrm{BP}$, we expressed it as the relative difference (right-arm BP $[\mathrm{R}]$ minus left-arm BP $[\mathrm{L}]: \mathrm{R}-\mathrm{L}$ ) and the absolute difference $(|\mathrm{R}-\mathrm{L}|)$. When comparing baseline and clinical characteristics including physical measurements, SBP and DBP between men and women, we used Student's t-test. In addition, when comparing cardiovascular risk factors and living habits between the two sexes, we used a chi-square test. Moreover, to identify correlations between the age, sex, cardiovascular risk factors, and the IAD in $\mathrm{BP}$, we used the Mann-Whitney U-test and Kruskal-Wallis H-test because the SBP and DBP did not follow the normal distribution. All statistical analyses were performed using SPSS ver. 18.0 (SPSS Inc., Chicago, IL, USA). A $\mathrm{P}$-value of $<0.05$ was considered statistically significant.

\section{RESULTS}

\section{Baseline and Clinical Characteristics of the}

\section{Patients}

Our clinical series of patients $(n=464)$ was composed of 261 men (56\%) and 203 women (44\%). The mean age of the patients was $53.0 \pm 8.8$ years in men and $54.1 \pm 9.1$ years in women. Compared with women, men showed lower high density lipoprotein-cholesterol, higher triglyceride, higher creatinine, more diabetes mellitus, a higher past history of smoking and drinking, higher 10-year Framingham cardiovascular risk scores, and greater IAD in SBP. Mean SBP in the right arm was $124.3 \pm$ $14.0 \mathrm{~mm} \mathrm{Hg}$ in men and $122.7 \pm 15.6 \mathrm{~mm} \mathrm{Hg}$ in women. But this difference did not reach statistical significance $(\mathrm{P}=0.226)$. Mean DBP in the right arm was $81.0 \pm 9.9 \mathrm{~mm} \mathrm{Hg}$ and $78.5 \pm 10.9 \mathrm{~mm}$ $\mathrm{Hg}$ in the corresponding order. This difference reached statistical significance $(\mathrm{P}=0.008)$. Mean SBP in the left arm was $122.0 \pm$ $13.1 \mathrm{~mm} \mathrm{Hg}$ in men and $121.0 \pm 14.9 \mathrm{~mm} \mathrm{Hg}$ in women. But this difference did not reach statistical significance $(\mathrm{P}=0.466)$. Mean DBP in the left arm was $79.5 \pm 9.7 \mathrm{~mm} \mathrm{Hg}$ and $77.2 \pm 10.7 \mathrm{~mm}$ $\mathrm{Hg}$ in the corresponding order. This difference reached statistical significance $(\mathrm{P}=0.019)$. The absolute mean $\mathrm{IAD}$ in SBP was $3.19 \pm 2.38 \mathrm{~mm} \mathrm{Hg}$ in men and $2.61 \pm 2.18 \mathrm{~mm} \mathrm{Hg}$ in women. This difference reached statistical significance $(P=0.002)$. The absolute mean IAD in DBP was $2.41 \pm 1.59 \mathrm{~mm} \mathrm{Hg}$ and $2.25 \pm$ $2.01 \mathrm{~mm} \mathrm{Hg}$ in the corresponding order. But this difference did not reach statistical significance $(\mathrm{P}=0.110)$ (Table 1$)$.

\section{The Distribution of the Inter-arm Difference in Blood Pressure}

The absolute mean IAD in SBP was $3.19 \pm 2.38 \mathrm{~mm} \mathrm{Hg}$ in men, whose distribution ranged between 0 and $11.5 \mathrm{~mm} \mathrm{Hg}$; there were 81 patients $(31.0 \%)$ with an IAD in SBP of $<2 \mathrm{~mm}$ $\mathrm{Hg}, 92$ (35.2\%) with an IAD in SBP of 2 to $4 \mathrm{~mm} \mathrm{Hg}, 46$ (17.6\%) with an IAD in SBP of 4 to $6 \mathrm{~mm} \mathrm{Hg}, 31$ (11.9\%) with an IAD in SBP of 6 to $8 \mathrm{~mm} \mathrm{Hg}, 6$ (2.3\%) with an IAD in SBP of 8 to 10 $\mathrm{mm} \mathrm{Hg}$, and 5 (1.9\%) with an IAD in SBP of $>10 \mathrm{~mm} \mathrm{Hg}$. These 
Table 1. Baseline and clinical characteristics of the patients

\begin{tabular}{|c|c|c|c|}
\hline Characteristic & Male $(n=261)$ & Female $(n=203)$ & P-value \\
\hline Age (y) & $53.0 \pm 8.8$ & $54.1 \pm 9.1$ & $0.203^{*}$ \\
\hline Height (cm) & $168.3 \pm 5.6$ & $155.7 \pm 5.7$ & $<0.001^{*}$ \\
\hline Weight (kg) & $70.4 \pm 9.2$ & $59.8 \pm 8.7$ & $<0.001^{*}$ \\
\hline Body mass index $\left(\mathrm{kg} / \mathrm{m}^{2}\right)$ & $24.8 \pm 2.7$ & $24.6 \pm 3.3$ & $0.583^{*}$ \\
\hline \multicolumn{4}{|l|}{ Lipid profile (mg/dL) } \\
\hline Total cholesterol & $182.1 \pm 34.9$ & $182.3 \pm 36.5$ & $0.979 *$ \\
\hline High density lipoprotein cholesterol & $48.3 \pm 11.7$ & $51.4 \pm 15.0$ & $0.013^{*}$ \\
\hline Low density lipoprotein cholesterol & $116.5 \pm 31.6$ & $116.1 \pm 32.2$ & $0.879 *$ \\
\hline Triglyceride & $147.8 \pm 108.5$ & $121.7 \pm 76.7$ & $0.004^{*}$ \\
\hline Serum creatinine $(\mathrm{mg} / \mathrm{dL})$ & $0.9 \pm 0.1$ & $0.8 \pm 0.1$ & $<0.001^{*}$ \\
\hline Metabolic syndrome & $76(29.1)$ & $71(35.0)$ & $0.192^{\dagger}$ \\
\hline Hypertension & $109(41.8)$ & $91(44.8)$ & $0.510^{\dagger}$ \\
\hline Diabetes & $33(12.6)$ & $14(6.9)$ & $0.045^{\dagger}$ \\
\hline Current smoking status & & & $<0.001^{\dagger}$ \\
\hline Yes & $113(43.3)$ & $2(1.0)$ & \\
\hline No & $148(56.7)$ & $201(99.0)$ & \\
\hline Pack years & $12.7 \pm 16.1$ & $0.2 \pm 1.9$ & \\
\hline Alcohol drinking & & & $<0.001^{\dagger}$ \\
\hline 3 times/wk & $170(65.1)$ & $179(88.2)$ & \\
\hline 4 times/wk & $91(34.9)$ & $24(11.8)$ & \\
\hline Framingham cardiac risk score & & & $<0.001^{*}$ \\
\hline$<10$ & $179(68.6)$ & $198(97.5)$ & \\
\hline 10 & $82(31.4)$ & $5(2.5)$ & \\
\hline Right systolic blood pressure (mm Hg) & $124.3 \pm 14.0$ & $122.7 \pm 15.6$ & $0.226^{*}$ \\
\hline Right diastolic blood pressure (mm Hg) & $81.0 \pm 9.9$ & $78.5 \pm 10.9$ & $0.008^{*}$ \\
\hline Left systolic blood pressure (mm Hg) & $122.0 \pm 13.1$ & $121.0 \pm 14.9$ & $0.466^{*}$ \\
\hline Left diastolic blood pressure (mm Hg) & $79.5 \pm 9.7$ & $77.2 \pm 10.7$ & $0.019^{*}$ \\
\hline Absolute mean IAD systolic blood pressure (mm Hg) & $3.19 \pm 2.38$ & $2.61 \pm 2.18$ & $0.002^{\ddagger}$ \\
\hline Absolute mean IAD diastolic blood pressureP (mm Hg) & $2.41 \pm 1.59$ & $2.25 \pm 2.01$ & $0.110^{\ddagger}$ \\
\hline
\end{tabular}

Values are presented as mean \pm SD or number (\%).

IAD: inter-arm difference.

*P-value by Student's t-test. ${ }^{\dagger} \mathrm{P}$-value by chi-square test. ${ }^{\ddagger} \mathrm{P}$-value by Mann-Whitney U-test.

results indicate that the $\mathrm{IAD}$ in $\mathrm{SBP}$ was $\leq 6 \mathrm{~mm} \mathrm{Hg}$ in $83.8 \%$ and $\leq 10 \mathrm{~mm} \mathrm{Hg}$ in $98.1 \%$ of male patients. The absolute mean IAD in SBP was $2.61 \pm 2.18 \mathrm{~mm} \mathrm{Hg}$ in women, whose distribution ranged between 0 and $9.5 \mathrm{~mm} \mathrm{Hg}$; there were 87 patients (42.9\%) with an IAD in SBP of $<2 \mathrm{~mm} \mathrm{Hg}, 68$ (33.5\%) with an IAD in
SBP of 2 to $4 \mathrm{~mm} \mathrm{Hg}, 25$ (12.3\%) with an IAD in SBP of 4 to $6 \mathrm{~mm} \mathrm{Hg}, 13$ (6.5\%) with an IAD in SBP of 6 to $8 \mathrm{~mm} \mathrm{Hg}, 10$ (4.9\%) with an IAD in SBP of 8 to $10 \mathrm{~mm} \mathrm{Hg}$, and 0 (0\%) with an IAD in SBP of $\geq 10 \mathrm{~mm} \mathrm{Hg}$. These results indicate that the $\mathrm{IAD}$ in SBP was $\leq 6 \mathrm{~mm} \mathrm{Hg}$ in $89.6 \%$ of female patients. 

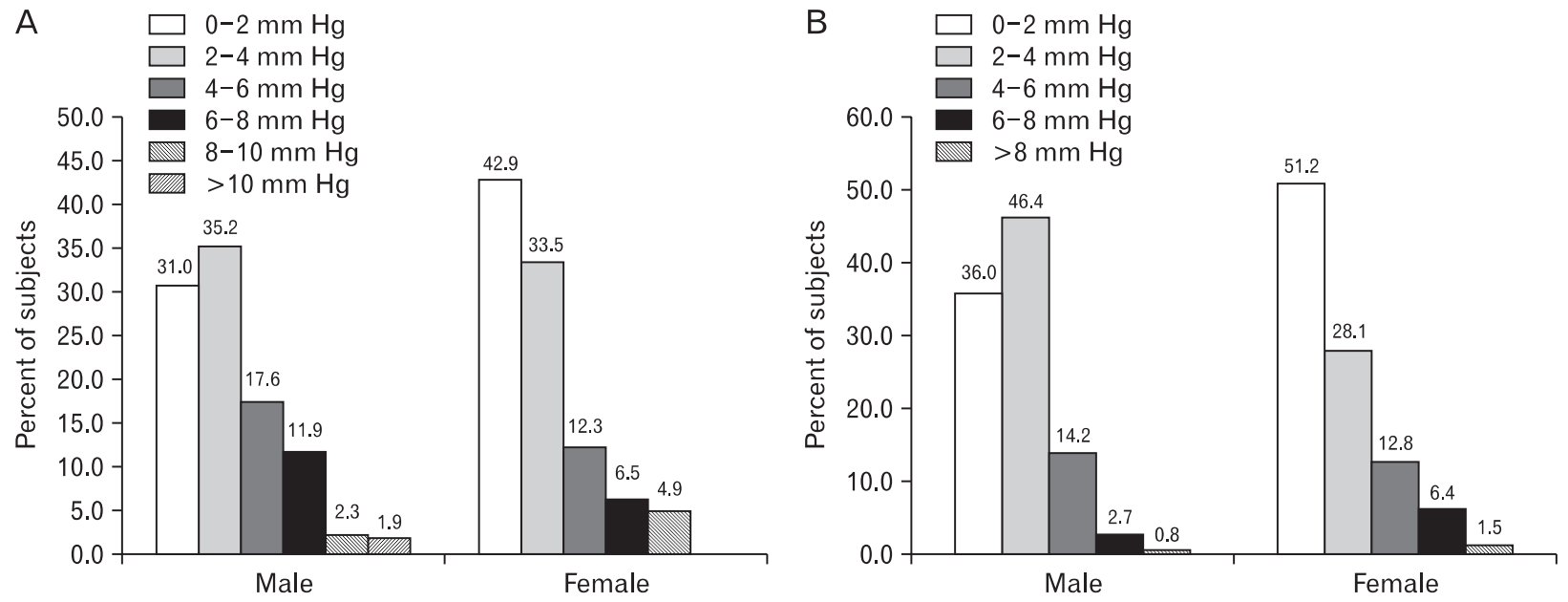

Figure 1. The inter-arm difference (IAD) in systolic blood pressure (SBP) (A) and diastolic blood pressure (DBP) (B). In male, there were $83.8 \%$ of patients with the IAD in SBP of $\leq 6 \mathrm{~mm} \mathrm{Hg}, 98.1 \%$ with the IAD in SBP of $\leq 10 \mathrm{~mm} \mathrm{Hg}, 96.5 \%$ with the IAD in DBP of $\leq 6 \mathrm{~mm} \mathrm{Hg}$ and $0 \%$ with the IAD in DBP of $>10 \mathrm{~mm} \mathrm{Hg}$. In female, there were $89.6 \%$ of patients with the IAD in SBP of $\leq 6 \mathrm{~mm} \mathrm{Hg}, 92.1 \%$ with the IAD in $\mathrm{DBP}$ of $\leq 6 \mathrm{~mm} \mathrm{Hg}$ and $0 \%$ with the $\mathrm{IAD}$ in $\mathrm{SBP}$ of $>10 \mathrm{~mm} \mathrm{Hg}$ or the $\mathrm{IAD}$ in $\mathrm{DBP}$ of $>10 \mathrm{~mm} \mathrm{Hg}$.

The absolute mean IAD in DBP was $2.41 \pm 1.59 \mathrm{~mm} \mathrm{Hg}$ in men, whose distribution ranged between 0 and $9 \mathrm{~mm} \mathrm{Hg}$; there were 94 patients (36.0\%) with an IAD in DBP of $<2 \mathrm{~mm} \mathrm{Hg}$, 121 (46.4\%) with an IAD in DBP of 2 to $4 \mathrm{~mm} \mathrm{Hg}, 37$ (14.2\%) with an IAD in DBP of 4 to $6 \mathrm{~mm} \mathrm{Hg}, 7$ (2.7\%) with an IAD in $\mathrm{DBP}$ of 6 to $8 \mathrm{~mm} \mathrm{Hg}$, and $2(0.8 \%)$ with an IAD in DBP of $\geq 8$ $\mathrm{mm} \mathrm{Hg}$. These results indicate that the IAD in DBP was $\leq 6 \mathrm{~mm}$ $\mathrm{Hg}$ in $96.5 \%$ of male patients. The absolute mean IAD in DBP was $2.25 \pm 2.01 \mathrm{~mm} \mathrm{Hg}$ in women, whose distribution ranged between 0 and $9 \mathrm{~mm} \mathrm{Hg}$; there were 104 patients (51.2\%) with an IAD in DBP of $<2 \mathrm{~mm} \mathrm{Hg}, 57$ (28.1\%) with an IAD in DBP of 2 to $4 \mathrm{~mm} \mathrm{Hg}, 26(12.8 \%)$ with an IAD in DBP of 4 to $6 \mathrm{~mm}$ $\mathrm{Hg}, 13$ (6.4\%) with an IAD in DBP of 6 to $8 \mathrm{~mm} \mathrm{Hg}$ and 3 (1.5\%) with an IAD in DBP of $\geq 8 \mathrm{~mm} \mathrm{Hg}$. These results indicate that the IAD in DBP was $\leq 6 \mathrm{~mm} \mathrm{Hg}$ in $92.1 \%$ of female patients (Figure 1).

\section{Factors Affecting the Inter-arm Difference in Blood Pressure}

In men aged 40 years or older, we examined whether such factors as age, hypertension, diabetes, metabolic syndrome, chronic renal disease, obesity index, smoking status, and heavy drinking would affect the IAD in BP. Only, IAD in SBP had a significant correlation with cardiovascular risk factors such as the 10-year Framingham cardiac risk scores and higher BP in men.
But this study showed that these other factors had no significant correlation with the IAD in SBP or DBP (Table 2).

In women aged 40 years or older, we examined whether such factors as age, diabetes, metabolic syndrome, chronic renal disease, obesity index, smoking status, heavy drinking, and Framingham scores would affect the IAD in BP. But this study showed that these factors had no significant correlation with the $\mathrm{IAD}$ in SBP or DBP. Only in the hypertension group where BP was higher was the IAD in SBP higher $(\mathrm{P}=0.018)$ (Table 3).

\section{The Correlation between Inter-arm Difference in Blood Pressure and the Severity of Blood Pressure}

To examine whether there is a correlation between the IAD in $\mathrm{BP}$ and the severity of $\mathrm{BP}$, the SBP and DBP were measured in both arms and the results were averaged. This showed that men with a higher SBP had a greater IAD in SBP $(r=0.274, \mathrm{P}<0.001)$ and a greater IAD in DBP $(r=0.171, \mathrm{P}=0.006)$ to a statistically significant extent. Similarly, men with a higher DBP had a greater $\mathrm{IAD}$ in SBP $(\mathrm{r}=0.180, \mathrm{P}=0.003)$ and a greater IAD in DBP $(r=$ $0.136, P=0.028)$ to a statistically significant extent. On the other hand, women with a higher SBP had a greater IAD in SBP ( $r=$ $0.278, \mathrm{P}<0.001)$ and a greater IAD in DBP $(\mathrm{r}=0.248, \mathrm{P}<0.001)$. But women with a higher DBP had no correlation with IAD in SBP and IAD in DBP (Table 4). 
Table 2. The absolute inter-arm difference in blood pressure in men

\begin{tabular}{|c|c|c|c|c|}
\hline \multirow{2}{*}{ Variable } & \multicolumn{2}{|c|}{ Systolic blood pressure (mm Hg) } & \multicolumn{2}{|c|}{ Diastolic blood pressure ( $\mathrm{mm} \mathrm{Hg}$ ) } \\
\hline & $|\mathrm{R}-\mathrm{L}|$ & P-value & $|\mathrm{R}-\mathrm{L}|$ & P-value \\
\hline \multicolumn{5}{|l|}{ Age (y) } \\
\hline$<45$ & $3.42 \pm 1.89$ & $0.363^{*}$ & $2.45 \pm 1.83$ & $0.052^{*}$ \\
\hline $45-54$ & $3.13 \pm 2.46$ & & $2.39 \pm 1.55$ & \\
\hline $55-64$ & $3.47 \pm 2.59$ & & $2.73 \pm 1.72$ & \\
\hline 65 & $2.59 \pm 1.92$ & & $1.76 \pm 0.98$ & \\
\hline \multicolumn{5}{|l|}{ Hypertension } \\
\hline Yes & $3.43 \pm 2.42$ & $0.126^{\dagger}$ & $2.43 \pm 1.59$ & $0.769^{\dagger}$ \\
\hline No & $3.01 \pm 2.34$ & & $2.40 \pm 1.61$ & \\
\hline \multicolumn{5}{|l|}{ Diabetes } \\
\hline Yes & $3.50 \pm 2.45$ & $0.430^{\dagger}$ & $2.61 \pm 1.37$ & $0.470^{\dagger}$ \\
\hline No & $3.15 \pm 2.37$ & & $2.39 \pm 1.63$ & \\
\hline \multicolumn{5}{|l|}{ Metabolic syndrome } \\
\hline Yes & $3.44 \pm 2.45$ & $0.283^{\dagger}$ & $2.47 \pm 1.77$ & $0.749^{\dagger}$ \\
\hline No & $3.09 \pm 2.35$ & & $2.40 \pm 1.53$ & \\
\hline \multicolumn{5}{|c|}{ Framingham risk score (\%) } \\
\hline$<10$ & $2.99 \pm 2.00$ & $0.049^{\dagger}$ & $2.43 \pm 1.60$ & $0.852^{\dagger}$ \\
\hline 10 & $3.62 \pm 3.02$ & & $2.39 \pm 1.61$ & \\
\hline \multicolumn{5}{|c|}{ Creatine clearance rate (mL/min) } \\
\hline$<60$ & $2.93 \pm 2.37$ & $0.669^{\dagger}$ & $2.29 \pm 1.91$ & $0.752^{\dagger}$ \\
\hline 60 & $3.21 \pm 2.38$ & & $2.43 \pm 1.58$ & \\
\hline \multicolumn{5}{|c|}{ Body mass index $\left(\mathrm{kg} / \mathrm{m}^{2}\right)$} \\
\hline$<25$ & $3.21 \pm 2.50$ & $0.757^{\dagger}$ & $2.55 \pm 1.69$ & $0.155^{\dagger}$ \\
\hline 25 & $3.15 \pm 2.26$ & & $2.27 \pm 1.49$ & \\
\hline \multicolumn{5}{|c|}{ Current smoking status } \\
\hline Yes & $3.27 \pm 2.54$ & $0.632^{\dagger}$ & $2.37 \pm 1.53$ & $0.715^{\dagger}$ \\
\hline No & $3.13 \pm 2.26$ & & $2.45 \pm 1.66$ & \\
\hline \multicolumn{5}{|c|}{ Alcohol drinking (times/wk) } \\
\hline 3 & $3.05 \pm 2.33$ & $0.184^{\dagger}$ & $2.45 \pm 1.52$ & $0.627^{\dagger}$ \\
\hline 4 & $3.46 \pm 2.46$ & & $2.35 \pm 1.74$ & \\
\hline
\end{tabular}

Values are presented as mean \pm SD. Absolute difference: right-arm BP (R) minus left-arm BP (L).

${ }^{*}$ P-value by Kruskal-Wallis H-test. ${ }^{\dagger} \mathrm{P}$-value by Mann-Whitney U-test.

\section{DISCUSSION}

In non-cardiovascular, adult patients aged 40 years or older who visited the outpatient clinic of our clinical department, we measured simultaneously the BP in both arms using an automatic electronic sphygmomanometer. This showed not only that the absolute mean IAD in SBP was $3.19 \pm 2.38 \mathrm{~mm} \mathrm{Hg}$ in men and $2.61 \pm 2.18 \mathrm{~mm} \mathrm{Hg}$ in women but also that the absolute mean $\mathrm{IAD}$ in DBP was $2.41 \pm 1.59 \mathrm{~mm} \mathrm{Hg}$ in men and $2.25 \pm 2.01 \mathrm{~mm}$ $\mathrm{Hg}$ in women. Of the male patients, $1.9 \%$ had an IAD in SBP 
Table 3. The absolute inter-arm difference in blood pressure in women

\begin{tabular}{|c|c|c|c|c|}
\hline \multirow{2}{*}{ Variable } & \multicolumn{2}{|c|}{ Systolic blood pressure (mm Hg) } & \multicolumn{2}{|c|}{ Diastolic blood pressure ( $\mathrm{mm} \mathrm{Hg}$ ) } \\
\hline & $|\mathrm{R}-\mathrm{L}|$ & P-value & $|\mathrm{R}-\mathrm{L}|$ & P-value \\
\hline \multicolumn{5}{|l|}{ Age (y) } \\
\hline$<45$ & $1.93 \pm 1.73$ & $0.072^{*}$ & $2.02 \pm 1.42$ & $0.187^{*}$ \\
\hline $45-54$ & $2.57 \pm 2.13$ & & $2.41 \pm 2.15$ & \\
\hline $55-64$ & $3.12 \pm 2.44$ & & $2.43 \pm 2.23$ & \\
\hline 65 & $2.20 \pm 1.88$ & & $1.48 \pm 1.13$ & \\
\hline \multicolumn{5}{|l|}{ Hypertension } \\
\hline Yes & $3.01 \pm 2.17$ & $0.018^{\dagger}$ & $2.46 \pm 2.18$ & $0.209^{\dagger}$ \\
\hline No & $2.29 \pm 2.14$ & & $2.10 \pm 1.86$ & \\
\hline \multicolumn{5}{|l|}{ Diabetes } \\
\hline Yes & $2.75 \pm 2.42$ & $0.805^{\dagger}$ & $2.14 \pm 2.15$ & $0.824^{\dagger}$ \\
\hline No & $2.60 \pm 2.17$ & & $2.27 \pm 2.01$ & \\
\hline \multicolumn{5}{|l|}{ Metabolic syndrome } \\
\hline Yes & $2.31 \pm 1.74$ & $0.150^{\dagger}$ & $2.06 \pm 1.76$ & $0.312^{\dagger}$ \\
\hline No & $2.78 \pm 2.38$ & & $2.35 \pm 2.14$ & \\
\hline \multicolumn{5}{|c|}{ Framingham risk score (\%) } \\
\hline$<10$ & $2.63 \pm 2.20$ & $0.250^{\dagger}$ & $2.29 \pm 2.03$ & $0.235^{\dagger}$ \\
\hline 10 & $1.50 \pm 5.00$ & & $1.20 \pm 0.84$ & \\
\hline \multicolumn{5}{|c|}{ Creatine clearance rate $(\mathrm{mL} / \mathrm{min})$} \\
\hline$<60$ & $2.57 \pm 2.19$ & $0.597^{\dagger}$ & $2.38 \pm 2.13$ & $0.113^{\dagger}$ \\
\hline 60 & $2.77 \pm 2.16$ & & $1.83 \pm 1.47$ & \\
\hline \multicolumn{5}{|c|}{ Body mass index $\left(\mathrm{kg} / \mathrm{m}^{2}\right)$} \\
\hline$<25$ & $2.44 \pm 2.13$ & $0.185^{\dagger}$ & $2.13 \pm 1.87$ & $0.257^{\dagger}$ \\
\hline 25 & $2.86 \pm 2.25$ & & $2.45 \pm 2.20$ & \\
\hline \multicolumn{5}{|l|}{ Current smoking status } \\
\hline Yes & $1.25 \pm 0.35$ & $0.376^{\dagger}$ & $1.50 \pm 0.70$ & $0.594^{\dagger}$ \\
\hline No & $2.62 \pm 2.19$ & & $2.27 \pm 2.02$ & \\
\hline \multicolumn{5}{|c|}{ Alcohol drinking (times/wk) } \\
\hline 3 & $2.60 \pm 2.18$ & $0.778^{\dagger}$ & $2.32 \pm 2.06$ & $0.249^{\dagger}$ \\
\hline 4 & $2.73 \pm 2.25$ & & $1.81 \pm 1.83$ & \\
\hline
\end{tabular}

Values are presented as mean \pm SD. Absolute difference: right-arm BP (R) minus left-arm BP (L).

*P-value by Kruskal-Wallis H-test. ${ }^{\dagger} \mathrm{P}$-value by Mann-Whitney U-test.

of $>10 \mathrm{~mm} \mathrm{Hg}$. But there were no women with an IAD in SBP of $>10 \mathrm{~mm} \mathrm{Hg}$. In addition, $3.5 \%$ of male patients and $7.9 \%$ of female patients had an IAD in DBP of $>6 \mathrm{~mm} \mathrm{Hg}$. These results indicate that most of our clinical series of patients had IAD SBP measurements of $<10 \mathrm{~mm} \mathrm{Hg}$ and IAD DBP measurements of
$<6 \mathrm{~mm} \mathrm{Hg}$. We also attempted to identify the factors affecting the IAD in BP. This showed that the IAD in SBP was greater in men with 10\% higher Framingham cardiac risk scores or higher $\mathrm{BP}$ and women with higher BP. However, the IAD in BP had no significant correlation with age, obesity index, smoking history, 
Table 4. The correlation between the inter-arm difference in BP and the severity of BP

\begin{tabular}{lccccc}
\hline & \multicolumn{2}{c}{ Inter-arm difference SBP } & & \multicolumn{2}{c}{ Inter-arm difference DBP } \\
\cline { 6 - 6 } \cline { 5 - 6 } & $\mathrm{r}$ & P-value & & $\mathrm{r}$ & P-value \\
\hline Male & & & & & \\
Mean SBP & 0.274 & $<0.001$ & & 0.171 & 0.006 \\
Mean DBP & 0.180 & 0.003 & & 0.136 & 0.028 \\
Female & & & & & \\
Mean SBP & 0.287 & $<0.001$ & & 0.075 & 0.285 \\
Mean DBP & 0.248 & $<0.001$ & 0.033 & 0.644 \\
\hline
\end{tabular}

r: Spearman correlation coefficient.

BP: blood pressure, SBP: systolic blood pressure, DBP: diastolic blood pressure.

amount of drinking, hyperlipidemia, diabetes mellitus, metabolic syndrome, or renal functions.

In a clinical study about the significance of the IAD in $\mathrm{BP}$, hypertensive patients were followed up in a primary care setting during a 10-year period. This showed that cardiovascular morbidity and mortality were higher when the IAD in SBP was greater, with no respect to other cardiovascular risk factors. ${ }^{8)}$ Following a systematic review and a meta-analysis of 20 cases, when the IAD in SBP was greater than $15 \mathrm{~mm} \mathrm{Hg}$, death and overall mortality were increased because of peripheral vascular diseases, the recurrence of cerebral infarction, and cardiovascular diseases. It has also been reported that the incidence of peripheral vascular diseases was associated with an IAD in SBP of $\geq 10 \mathrm{~mm}$ $\mathrm{Hg}^{9)}$

In the current study, the IAD in SBP ranged between 0 and $11.5 \mathrm{~mm} \mathrm{Hg}$ in men and between 0 and $9.5 \mathrm{~mm} \mathrm{Hg}$ in women. In addition, our results also showed that the IAD in DBP ranged between 0 and $9 \mathrm{~mm} \mathrm{Hg}$ in both sexes. This is in agreement with the reports of Orme et al. ${ }^{10)}$ who simultaneously measured BP in both arms using an automatic electronic sphygmomanometer in patients without cardiovascular diseases or stroke, as we did for the current study. According to a study conducted in outpatients who visited an emergency care center, however, 53\% had an IAD in $\mathrm{BP}$ (SBP or DBP) of $>10 \mathrm{~mm} \mathrm{Hg}$ and $19 \%$ had an IAD in BP of $>20 \mathrm{~mm} \mathrm{Hg}{ }^{11)}$ Presumably, this might not only be because two independent observers sequentially measured the IAD in $\mathrm{BP}$ but also because the study enrolled patients with many problems in an emergency care setting.
Our results showed that the absolute mean IAD in SBP was $3.19 \pm 2.38 \mathrm{~mm} \mathrm{Hg}$, and the absolute mean IAD in DBP was $2.41 \pm 1.59 \mathrm{~mm} \mathrm{Hg}$ in men. In women, these values were 2.61 $\pm 2.18 \mathrm{~mm} \mathrm{Hg}$ and $2.25 \pm 2.01 \mathrm{~mm} \mathrm{Hg}$ in the corresponding order. Consistent with our results, most of the studies have shown that there is little IAD in BP. Pesola et al. ${ }^{12)}$ also simultaneously measured BP in both arms in patients with normal BP. These authors reported that the mean IAD in SBP was $0.59 \mathrm{~mm} \mathrm{Hg}$ and the mean IAD in DBP was $0.91 \mathrm{~mm} \mathrm{Hg}$. This suggests that there would be almost no IAD in BP unless there is vascular anomaly. There would only be some differences in BP because of differences in the order of measurement based on the psychological and emotional status of patients, the thickness between the two arms, and other mechanical conditions. Eguchi et al. ${ }^{13)}$ also reported that there was almost no IAD in BP, but added that it was present only in patients with arterial occlusive disease. They also noted that BP in the right arm would be slightly higher than the left arm in right-handed patients. Moreover, according to Kim et al., ${ }^{14)}$ there was no IAD in BP and the BP was measured slightly lower due to the difference in the order of measurement in the second session in Korean college students. These authors also noted that BP in the right arm was measured slightly higher than the left hand because of the difference in BP due to the dominance of the hand.

Simultaneous BP measurements should be obtained from both arms for the accurate measurement of BP. However, it is not easy to simultaneously measure BP using manual methods. An automatic electronic sphygmomanometer is therefore used. But an automatic device causes many measurement errors in patients with arrhythmia. Clinicians should therefore consider this when measuring BP in patients with arrhythmia. Lohmann et al. ${ }^{15)}$ measured BP sequentially for each arm using manual methods and simultaneously for both arms using an automatic device in patients with a mean age of 60 years who had more than two cardiovascular risk factors. Following a comparison between the two methods, the above authors reported that the latter methods were more accurate. Moreover, according to them, IAD in SBP of $>20 \mathrm{~mm} \mathrm{Hg}$ or IAD in DBP of > $10 \mathrm{~mm} \mathrm{Hg}$ was seen in $9 \%$ of patients who used the former methods and $3 \%$ of those who used the latter methods.

In the current study, we examined the factors affecting the $\mathrm{IAD}$ in $\mathrm{BP}$ even in the absence of specific cardiovascular diseases. 
This showed that the IAD in SBP was relatively greater in men with more than 10\% higher 10-year Framingham cardiac risk scores and higher BP and women with higher BP. There is also an epidemiological study reporting that the IAD in BP was relatively greater in patients with higher BP, a higher systolic pressure in particular, and those with a higher obesity index. ${ }^{16)}$ In 2006, Clark et $\mathrm{al}^{17)}$ reported that the IAD in $\mathrm{BP}$ was significantly greater in patients with cardiovascular disease or hypertensive patients.

Our results showed that there was no significant IAD in BP in ambulatory patients without cardiovascular disease. Clinicians should consider the risk of developing atherosclerotic cardiovascular diseases when they encounter patients with an $\mathrm{IAD}$ in $\mathrm{SBP}$ of $>10 \mathrm{~mm} \mathrm{Hg}$ or an $\mathrm{IAD}$ in $\mathrm{DBP}$ of $>6 \mathrm{~mm} \mathrm{Hg}$.

\section{CONFLICT OF INTEREST}

No potential conflict of interest relevant to this article was reported.

\section{REFERENCES}

1. Chobanian AV, Bakris GL, Black HR, Cushman WC, Green LA, Izzo JL Jr, et al. The Seventh Report of the Joint National Committee on Prevention, Detection, Evaluation, and Treatment of High Blood Pressure: the JNC 7 report. JAMA 2003;289:2560-72.

2. PetrieJC, O’BrienET, LittlerWA, de Swiet M. Recommendations on blood pressure measurement. Br Med J (Clin Res Ed) 1986;293:611-5.

3. Clark CE, Powell RJ. The differential blood pressure sign in general practice: prevalence and prognostic value. Fam Pract 2002;19:439-41.

4. Agarwal R, Bunaye Z, Bekele DM. Prognostic significance of between-arm blood pressure differences. Hypertension 2008; 51:657-62.

5. Kim WB, Oh MK, Lee SH, Roh J, Kim HG, Kim JY, et al. A case of successful correction of subclavian steal syndrome by percutaneous transluminal angioplasty with stenting who found incidentally significant interarm blood pressure difference. Korean J Fam Med 2009;30:979-84.
6. Harrison EG Jr, Roth GM, Hines EA Jr. Bilateral indirect and direct arterial pressures. Circulation 1960;22:419-36.

7. Wilson PW, D’Agostino RB, Levy D, Belanger AM, Silbershatz H, Kannel WB. Prediction of coronary heart disease using risk factor categories. Circulation 1998;97:183747.

8. Clark CE, Taylor RS, Shore AC, Campbell JL. The difference in blood pressure readings between arms and survival: primary care cohort study. BMJ 2012;344:e1327.

9. Clark CE, Taylor RS, Shore AC, Ukoumunne OC, Campbell JL. Association of a difference in systolic blood pressure between arms with vascular disease and mortality: a systematic review and meta-analysis. Lancet 2012;379:90514.

10. Orme S, Ralph SG, Birchall A, Lawson-Matthew P, McLean $\mathrm{K}$, Channer KS. The normal range for inter-arm differences in blood pressure. Age Ageing 1999;28:537-42.

11. Singer AJ, Hollander JE. Blood pressure: assessment of interarm differences. Arch Intern Med 1996;156:2005-8.

12. Pesola GR, Pesola HR, Nelson MJ, Westfal RE. The normal difference in bilateral indirect blood pressure recordings in normotensive individuals. Am J Emerg Med 2001;19:43-5.

13. Eguchi K, Yacoub M, Jhalani J, Gerin W, Schwartz JE, Pickering TG. Consistency of blood pressure differences between the left and right arms. Arch Intern Med 2007;167: 388-93.

14. Kim HJ, Won CW, Ann ES, Jung JJ, Kim BS, Choi HR. Blood pressure difference between right and left arms of some college freshmen.J Korean Acad Fam Med 2003;24:166-71.

15. Lohmann FW, Eckert S, Verberk WJ. Interarm differences in blood pressure should be determined by measuring both arms simultaneously with an automatic oscillometric device. Blood Press Monit 2011;16:37-42.

16. Arnett DK, Tang W, Province MA, Oberman A, Ellison RC, Morgan D, et al. Interarm differences in seated systolic and diastolic blood pressure: the Hypertension Genetic Epidemiology Network study.J Hypertens 2005;23:1141-7.

17. Clark CE, Campbell JL, Evans PH, Millward A. Prevalence and clinical implications of the inter-arm blood pressure difference: a systematic review. J Hum Hypertens 2006;20: 923-31. 